\title{
CARACTERIZAÇÃO DE GEOAMBIENTES DA FLORESTA NACIONAL DO PURUS, AMAZÔNIA OCIDENTAL: UMA CONTRIBUIÇÃO AO PLANO DE MANEJO'
}

\author{
Pedro Christo Brandão ${ }^{2}$,Vicente Paulo Soares ${ }^{3}$, Felipe Nogueira Bello Simas ${ }^{4}$, Carlos Ernesto \\ Gonçalves Reynaud Schaefer ${ }^{5}$, Agostinho Lopes de Souza ${ }^{3}$ e Bruno Araujo Furtado de Mendonça ${ }^{4}$
}

\begin{abstract}
RESUMO - A falta de estudos básicos necessários para o plano de manejo vem retardando a implementação efetiva de diversas Unidades de Conservação na região amazônica. Neste trabalho, interpretações de imagens orbitais e semiorbitais aliadas a trabalhos de campo foram utilizadas para a caracterização geoambiental da Floresta Nacional (FLONA) do Purus. Através da geração de mapas temáticos, criou-se uma base digital georreferenciada que constitui a primeira plataforma para o SIG da FLONA. Foram identificados quatro geoambientes principais: Platôs Dissecados com Mata sobre Latossolos e Argissolos; Encostas e Rampas com Mata sobre Argissolos; Planícies Aluviais Eutróficas com Neossolos Flúvicos e Gleissolos; e Planícies Aluviais Distróficas com Gleissolos. Os aluviões holocênicos na área sob influência do rio Purus são ricos em nutrientes (eutróficos), com influência de sedimentos subandinos. Em contraste, a maior parte da FLONA possui solos extremamente ácidos e pobres em nutrientes (distróficos), formados a partir do intemperismo de sedimentos da Formação Solimões. O manejo dessas áreas deve visar ao incremento do aporte de biomassa na superfície dos solos, aumentando a eficiência da ciclagem de nutrientes pela vegetação, já que a reserva química natural é extremamente baixa.
\end{abstract}

Palavras-chave: Unidades de Conservação, SIG e Solos.

\section{GEOENVIRONMENTS OF THE PURUS NATIONAL FOREST: A CONTRIBUTION TO THE MANAGEMENT PLAN}

\begin{abstract}
The lack of basic studies for the elaboration of management plans has delayed the effective implementation of conservation units in the Amazon region. In this work, the interpretation of orbital and sub-orbital images, together with field surveys were used for the geoenvironmental characterization of the Purus National Forest (PNF). A georreferenced digital database composed of thematic maps was produced and constitutes the base of a GIS for the PNF. Four geoenvironments were identified and mapped: Dissecated Plateaux with forest vegetation on Latosols and Argisols; Forested slopes on Argisols; Alluvial plains with eutric soils; Alluvial plains with dystric soils. The holocenic alluviums influenced by the Purus River are eutric, and receive sub-Andenean sediments. On the other hand, most of the PNF has extremely poor and acid soils related to the Solimões Formation. Since the nutrient levels in the mineral substrate are very low, the management of these areas should seek the increment of biomass in the system, which would enhance nutrient cycling by the vegetation since the nutrient levels in the mineral substrate are very low.
\end{abstract}

Keywords: Conservation Units, GIS and Soils.

\footnotetext{
${ }^{1}$ Recebido em 13.02.2008 e aceito para publicação em 14.10.2009.

${ }^{2}$ Centro Universitário de Caratinga, UNEC, Brasil. E-mail: <pedrocbrandao@gmail.com>.

${ }^{3}$ Departamento de Engenharia Floresta, Universidade Federal de Viçosa - Vicosa, MG - Brasil. E-mail: <vicente@ufv.br> e<alsouzaa@gmail.com>.

${ }^{4}$ Programa de Pós-Graduação em Solos e Nutrição de Plantas, Departamento de Solos, Universidade Federal de Viçosa, UFV, Brasil.E-mail: <fsimass@yahoo.com.br>e < brunoafmendonca@gmail.com>.

${ }^{5}$ Departamento de Solos, Universidade Federal de Viçosa - Vicosa, MG - Brasil. E-mail: <carlos.schafer@ufv.br>.
} 


\section{INTRODUÇÃO}

A Amazônia Legal compreende 5,1 milhões de $\mathrm{km}^{2}$, dos quais $12,1 \%$ estão protegidos por Unidades de Conservação (UCs). Porém, por falta de estudos básicos necessários, a maioria dessas UCs não foi efetivamente implantada e pouco tem contribuído para a conservação ambiental da região (ISA, 2004). De acordo com o Sistema Nacional de Unidades de Conservação (BRASIL, 2000), toda UC deve dispor de um plano de manejo, o qual deve ser elaborado no prazo máximo de cinco anos a partir da publicação do Decreto de sua criação. Esse documento técnico deve estabelecer as diferentes zonas e normas de uso visando ao manejo sustentável dos recursos naturais, bem como prever a implantação das estruturas físicas necessárias à gestão da Unidade (BRASIL, 2000).

As técnicas de sensoriamento remoto, amplamente utilizadas desde a década de 1970, têm trazido grande contribuição para o mapeamento e monitoramento dos recursos naturais na Amazônia (ESPIRITO-SANTO e SHIMABUKURO, 2005). Atualmente, os sistemas de informações geográficas (SIG) permitem a confecção de mapas temáticos e a quantificação das relações espaciais entre as feições mapeadas. Através dos SIGs, é possível ordenar áreas homogêneas em relação a atributos de interesse (cobertura vegetal, solos, relevo, sítios de interesse cultural, grau de antropização etc.), formando unidades básicas de planejamento. A criação de uma base cartográfica digital acurada permite a integração em tempo real dos dados das diferentes etapas do plano de manejo como inventários florísticos, faunísticos, dados sócioeconômicos, bem como seu acompanhamento temporal. A utilização dessas técnicas é indispensável para promover a conservação, manutenção ou ampliação das áreas protegidas, bem como de sua diversidade (MARTINS, 1999). Portanto, a interpretação de imagens constitui uma etapa obrigatória do processo de elaboração de planos de manejo (IBAMA, 2003).

Este trabalho objetivou caracterizar os geoambientes da Floresta Nacional (FLONA) do Purus, AM, identificando suas principais limitações e potenciais de uso, visando gerar uma base de informações para subsidiar a elaboração do plano de manejo, atendendo às especificações do Roteiro Metodológico para Elaboração de Planos de Manejo em Florestas Nacionais (IBAMA, 2003).

R. Árvore, Viçosa-MG, v.34, n.1, p.115-126, 2010

R. Árvore, Viçosa-MG, v.34, n.1, p.115-126, 2010

\section{MATERIAL E MÉTODOS}

\subsection{Caracterização da Área de Estudo}

A FLONA do Purus localiza-se no Município de Pauini, AM, entre os rios Purus e Inauini e o igarapé Teuini (latitudes $8^{\circ} 1^{\prime} 32^{\prime \prime}$ e $8^{\circ} 34^{\prime} 8^{\prime \prime}$ sul e longitudes $68^{\circ} 4^{\prime} 21^{\prime \prime}$ e $67^{\circ} 17^{\prime} 31^{\prime \prime}$ W. Gr.), compreendendo aproximadamente 256.000 ha (Figura 1). Em sua porção oeste, faz divisa com a FLONA Mapiá-Inauini, formando uma área protegida contínua de mais de 500.000 ha. Na porção noroeste, confronta com a Terra Indígena (TI) Inauini/Teuini, havendo uma sobreposição de 67.887 ha, o que corresponde a 26,5\% do território da FLONA (RICARDO, 2001).

Segundo a classificação de Köppen (1948), o clima da região é do tipo Am-tropical chuvoso (BRASIL, 1976), com temperatura média anual variando de 22,0 ${ }^{\circ} \mathrm{Ca} 26,0^{\circ} \mathrm{C}$ e totais anuais de evapotranspiração potencial da ordem de $1.350 \mathrm{~mm}$ a $1.500 \mathrm{~mm}$. A precipitação pluviométrica total anual varia de $1.750 \mathrm{~mm}$ a 2.250 $\mathrm{mm}$. O período com maior intensidade de chuvas compreende os meses de outubro a abril, enquanto o período mais seco ocorre de junho a agosto (IBGE, 1990). O acesso por via fluvial é facilitado durante o período das chuvas e praticamente limitado ao rio Purus na época mais seca.

Na maior parte da área, o relevo caracteriza-se por um planalto com topografia colinosa ou aplainada, dissecada em interflúvios tabulares, esculpida predominantemente sobre litologias sedimentares da Formação Solimões (Plio-Pleistoceno) constituídas de argilitos, siltitos e arenitos (BRASIL, 1976). Essas áreas comportam drenagem relativamente aprofundada e densa, com padrão subdentrítico, resultando em formas de relevo com 250-750 m de extensão, com vales de fundo chato (BRASIL, 1976).

Prevalece em toda a área a Floresta Ombrófila Densa (BRASIL, 1976). Nas áreas mais planas e elevadas (terra firme) e nas encostas dissecadas, a floresta é composta por árvores altas, com dossel alcançando $50 \mathrm{~m}$, sendo representada principalmente pela Dinizia excelsa, Manilkara hiberi, Anarcadium spp., Parkia pendula e Bertholletia excelsa, e sua regeneração natural varia de alta a média (IBGE, 1990). Já nas áreas de várzea, ao longo do igarapé Mapiá, ocorre uma mata ripária de menor porte, caracterizada por um dossel de 20 a $30 \mathrm{~m}$ de altura, 
apresentando poucas espécies emergentes e subbosque composto por um grande número de indivíduos jovens do estrato arbóreo, além de espécies herbáceas de rara beleza das famílias
Heliconiaceae e Zingiberaceae. Nessas áreas, as espécies que se destacam são as gameleiras (Ficus sp.), embaúbas (Cecropia sp.) e ingás-brancos (Inga sp.) (QUINET et al., 2005).

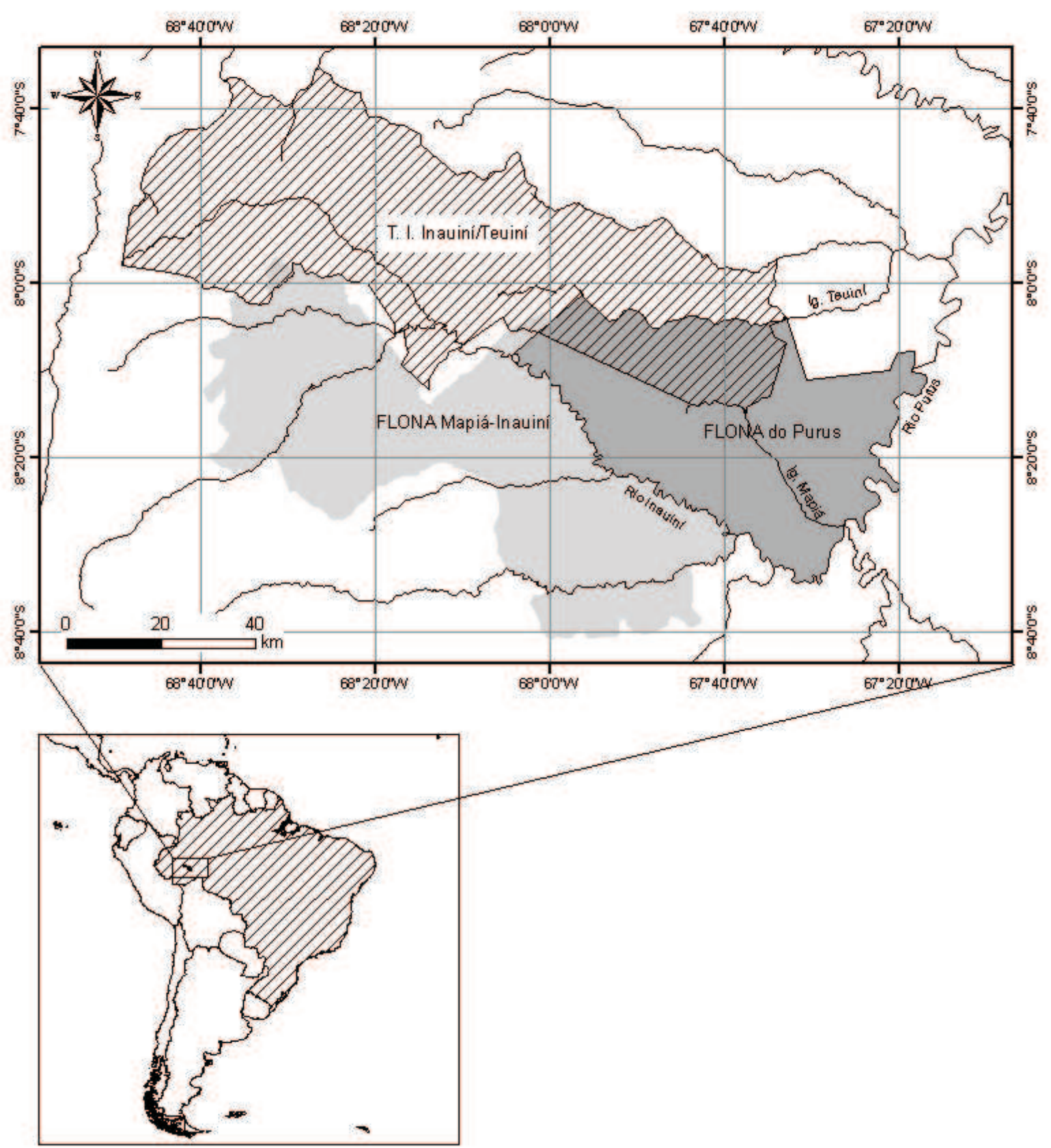

Figura 1 - Localização da FLONA do Purus, evidenciando a contiguidade com a FLONA Mapiá-Inauini e sobreposição com a Terra Indígena Inauiní/Teuini.

Figure 1 - Purus FLONA location, showing the contiguity with Mapiá-Inauiní FLONA and the superposition with Inauiníl Teuiní Indian Land. 


\subsection{Análise de imagens orbitais e suborbitais}

A separação das unidades geomorfológicas, pedológicas e fitofisionômicas e a digitalização da rede de drenagem foram realizadas a partir da interpretação de imagens Landsat 7-ETM ${ }^{+}$, bandas 4, 5 e 6, e do Modelo Digital de Elevação (MDE) da Shuttle Radar Topographic Mission - SRTM (Missão Topográfica por Radar Interferométrico). Para vetorização dos dados, foram utilizados uma mesa digitalizadora e o software ArcInfo $^{\circledR}$. Para a edição final dos dados, utilizaramse as ferramentas do menu Editor do software ArcGIS ${ }^{\circledR}$. Os mapas foram elaborados no sistema de projeção UTM e datum SAD 69, com resolução compatível com a escala de 1:100.000.

\subsection{Coleta, análise e classificação dos solos}

Com base nos padrões identificados nas imagens orbitais (Landsat $\mathrm{ETM}^{+}$) e suborbitais (SRTM) e nas características gerais da paisagem, foram amostrados seis perfis de solos em áreas representativas das unidades geoambientais da FLONA do Purus, concentrados ao longo das principais drenagens da UC em função da enorme extensão desta e da extrema dificuldade de acesso a outras áreas (Tabela 1).

Os perfis de solos foram coletados e descritos conforme Lemos e Santos (1984). Posteriormente, as amostras foram secas ao ar, destorroadas e passadas em peneira de $2 \mathrm{~mm}$, obtendo-se a terra fina seca ao ar (TFSA).

Amostras de TFSA foram submetidas às seguintes análises físicas e químicas de acordo com Embrapa (1997): $\mathrm{pH}$ em água; $\mathrm{Ca}^{2+}, \mathrm{Mg}^{2+} \mathrm{e} \mathrm{Al}^{3+}$ trocáveis (extraídos com $\mathrm{KCl} 1 \mathrm{~mol} / \mathrm{L})$; K, Na, P, Zn, Fe, Mn e Cu disponíveis (extraídos com Mehlich-1); acidez extraível $\left(\mathrm{H}^{+}+\mathrm{Al}^{3+}\right)$ (extraída com acetato de cálcio $1 \mathrm{~N}, \mathrm{pH} 7,0$ ); Ca, Mg, $\mathrm{Zn}, \mathrm{Fe}, \mathrm{Mn}$ e $\mathrm{Cu}$ determinados por espectrometria de absorção atômica; P disponível por fotocolorimetria; $\mathrm{Na}$ e K por fotometria de chama; $\mathrm{Al} \mathrm{e}\left(\mathrm{H}^{+}+\mathrm{Al}^{3+}\right)$ por titulação com NaOH. O Carbono Orgânico Total foi determinado pelo método de Walkley-Black e o teor de matéria orgânica, estimado pela equação: $\mathrm{MO}=$ C x 1,724 .

A granulometria dos solos foi obtida por dispersão com NaOH 0,1 mol/1, segundo o método da pipeta (EMBRAPA, 1997).

Os solos foram classificados até o quarto nível categórico, conforme o Sistema Brasileiro de Classificação de Solos (EMBRAPA, 2006).

\subsection{Elaboração do mapa geoambiental}

Com base na separação das unidades geomorfológicas e pedológicas, foi gerado o mapa de Geoambientes da FLONA do Purus. Foram agrupadas sob uma mesma denominação áreas com características similares em relação aos atributos avaliados (tipo de solos, topografia e cobertura vegetal), considerandose a escala cartográfica trabalhada (1:100.000), identificadas e descritas as características ecogeográficas observadas, assim como os problemas geoambientais associados (TRICART e KIEWITDEJONGE, 1992), conforme aplicado por Schaefer (1997) e Martins et al. (2006) na região amazônica. A edição dos mapas foi realizada em ambiente ArcGIS ${ }^{\circledR}$, compondo a base digital para o SIG da FLONA. Os mapas foram projetados no sistema UTM e datum SAD69.

Tabela 1 - Perfis de solos amostrados na FLONA do Purus, AM.

Table 1 - Soil profiles sampled in the Purus FLONA, Amazonas State.

\begin{tabular}{|c|c|c|c|c|c|}
\hline \multirow[t]{2}{*}{ Perfil } & \multirow[t]{2}{*}{ Classe de Solo } & \multirow[t]{2}{*}{ Região } & \multirow{2}{*}{$\begin{array}{l}\text { Compartimento } \\
\text { Geomorfológico }\end{array}$} & \multicolumn{2}{|c|}{ Coordenadas UTM } \\
\hline & & & & $\mathrm{E}$ & $\mathrm{N}$ \\
\hline$\overline{\mathrm{MP}} 1$ & $\begin{array}{c}\text { Latossolo Vermelho- } \\
\text { Amarelo Distrófico } \\
\text { típico (LVAd) }\end{array}$ & $\begin{array}{l}\text { Baixo Mapiá - Faz. } \\
\text { São Sebastião }\end{array}$ & Terra Firme - Platôs & 671367 & 9065886 \\
\hline MP 2 & $\begin{array}{l}\text { Cambissolo Háplico Ta } \\
\text { Eutrófico vértico (CXge) }\end{array}$ & $\begin{array}{l}\text { Baixo Mapiá - Faz. } \\
\text { São Sebastião }\end{array}$ & Várzea & 672518 & 9065089 \\
\hline MP 3 & $\begin{array}{l}\text { Argissolo Vermelho-Amarelo } \\
\text { Distrofico típico (PVAd) }\end{array}$ & $\begin{array}{l}\text { Alto Mapiá- } \\
\text { Vista Alegre }\end{array}$ & Terra Firme - Platôs & 652230 & 9084297 \\
\hline MP 4 & $\begin{array}{l}\text { Argissolo Vermelho-Amarelo } \\
\text { Distrofico típico (PVAd) }\end{array}$ & $\begin{array}{l}\text { Alto Mapiá - Vila } \\
\text { Céu do Mapiá }\end{array}$ & $\begin{array}{c}\text { Terra Firme - } \\
\text { Encostas e Rampas }\end{array}$ & 652761 & 9083251 \\
\hline MP 5 & $\begin{array}{l}\text { Gleissolo Háplico Tb } \\
\text { distrófico (GXbd) }\end{array}$ & $\begin{array}{l}\text { Alto Mapiá - Vila } \\
\text { Céu do Mapiá }\end{array}$ & Várzea & 652230 & 9083339 \\
\hline MP 6 & $\begin{array}{c}\text { Neossolo Flúvico Ta } \\
\text { Eutrófico gleico (RUge) }\end{array}$ & Praias do Purus & Várzea & 675700 & 9062101 \\
\hline
\end{tabular}

R. Árvore, Viçosa-MG, v.34, n.1, p.115-126, 2010 


\section{RESULTADOS E DISCUSSÃO}

A separação das unidades geomorfológicas e fitofisionômicas por sensoriamento remoto, juntamente com o levantamento de solos permitiu identificar quatro unidades geoambientais na FLONA do Purus (Figura 2): Platôs Dissecados com Mata sobre Latossolos e Argissolos;
Encostas e Rampas com Mata sobre Argissolos; Planícies Aluviais Distróficas com Gleissolos; e Planícies Aluviais Eutróficas com Neossolos Flúvicos e Gleissolos. As principais características ecogeográficas e os problemas geoambientais associados encontram-se resumidos na Tabela 2, sendo discutidos e apresentados a seguir.
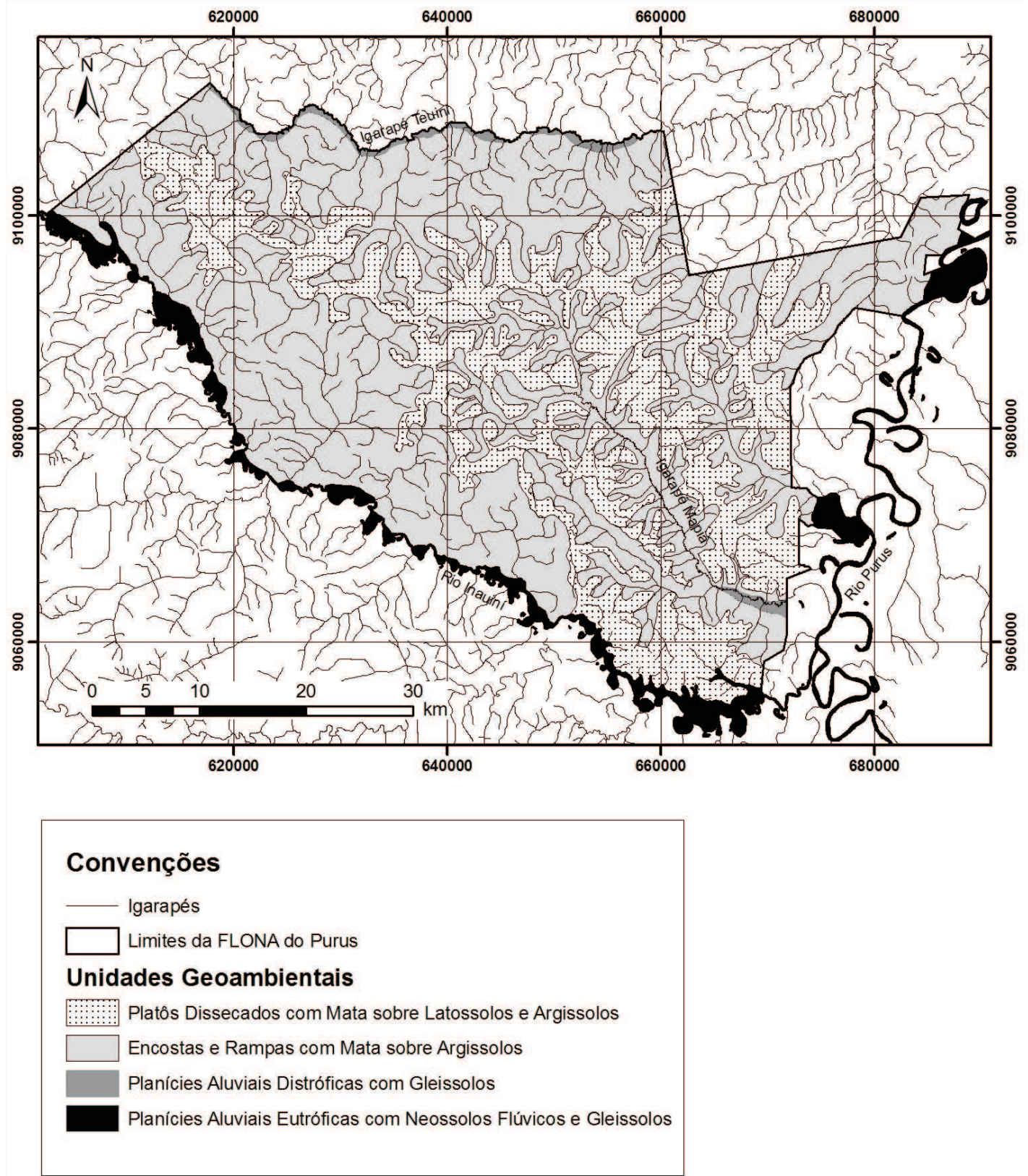

Figura 2 - Geoambientes da FLONA do Purus, AM.

Figure 2-Geoenvironmental units of the Purus FLONA, AM. 


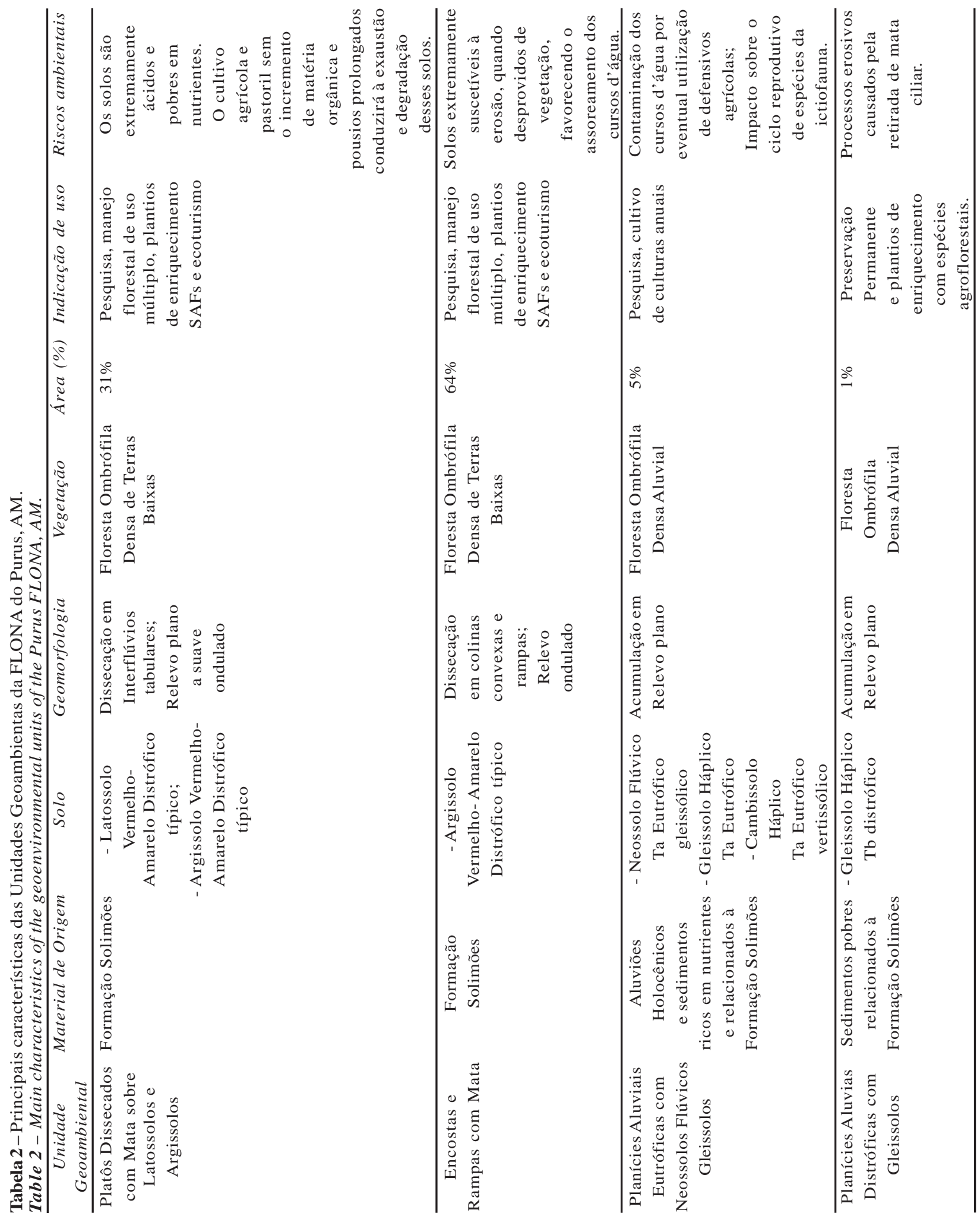

R. Árvore, Viçosa-MG, v.34, n.1, p.115-126, 2010 


\subsection{Platôs dissecados com mata sobre Latossolos e Argissolos}

As formas características desta unidade são os interflúvios tabulares com altitude variando de $160 \mathrm{~m}$ a $200 \mathrm{~m}$. Constituem as áreas de Terra Firme, representando aproximadamente $31 \%$ (78.840 ha) da área total da FLONA. Ocupam as porções mais altas da paisagem formando extensas superfícies suavemente dissecadas por pequenos igarapés. São áreas normalmente utilizadas para a retirada de recursos madeireiros e não madeireiros frequentemente usadas para a abertura de "roçados" e cultivo de culturas anuais.

Tabela 3-Características físicas dos solos da FLONA do Purus, AM.

Table 3 - Soil physical characteristics of the Purus FLONA, AM.

\begin{tabular}{|c|c|c|c|c|c|c|c|}
\hline \multirow[t]{3}{*}{ Horizonte } & \multirow{3}{*}{$\begin{array}{l}\text { Profundidade } \\
\quad(\mathrm{cm})\end{array}$} & \multicolumn{4}{|c|}{$<2 \mathrm{~mm}$} & \multirow{3}{*}{$\begin{array}{l}\text { Classe } \\
\text { Textural }\end{array}$} & \multirow{3}{*}{$\begin{array}{l}\text { Cor Seca } \\
\text { (Münsell) }\end{array}$} \\
\hline & & $\begin{array}{l}\text { Areia } \\
\text { Grossa }\end{array}$ & $\begin{array}{l}\text { Areia } \\
\text { Fina }\end{array}$ & Silte & Argila & & \\
\hline & & \multicolumn{4}{|c|}{$\mathrm{dag} / \mathrm{kg}$} & & \\
\hline \multicolumn{8}{|c|}{$\begin{array}{c}\text { Perfil MP } 1 \text { - LATOSSOLO VERMELHO-AMARELO Distrófico Típico } \\
\text { Áreas de Terra Firme do Baixo Mapiá (Fazenda São Sebastião) }\end{array}$} \\
\hline A & $0-8$ & 7 & 32 & 26 & 35 & Franco -agilosa & $10 \mathrm{YR} 5 / 4$ \\
\hline $\mathrm{AB}$ & $8-15$ & 5 & 25 & 32 & 38 & Franco-argilosa & 10 YR $6 / 6$ \\
\hline $\mathrm{Bw}_{1}$ & $15-60$ & 4 & 24 & 28 & 44 & Argila & 10 YR $6 / 6$ \\
\hline $\mathrm{Bw}_{2}$ & $60-80^{+}$ & 4 & 23 & 23 & 50 & Argila & $10 \mathrm{YR} 6 / 6$ \\
\hline \multicolumn{8}{|c|}{$\begin{array}{l}\text { Perfil MP } 2 \text { - CAMBISSOLO HÁPLICO Ta Eutrófico vértico } \\
\text { ies Aluviais Eutróficas (Várzea do Baixo Mapiá - Faz. São Sebastião) }\end{array}$} \\
\hline $\mathrm{A}$ & $0-8$ & 0 & 8 & 46 & 46 & Argila-siltosa & 10 YR $6 / 4$ \\
\hline $\mathrm{Bi}$ & $8-20$ & 0 & 9 & 56 & 35 & Franco-argilo-siltosa & $10 \mathrm{YR} 6 / 4$ \\
\hline $\mathrm{C}_{1}$ & $20-40$ & 0 & 8 & 64 & 28 & Franco-argilo-siltosa & 10 YR $6 / 4$ \\
\hline $\mathrm{C}_{2}$ & $40-80^{+}$ & 0 & 7 & 64 & 29 & Franco-argilo-siltosa & 10 YR 6/4 \\
\hline \multicolumn{8}{|c|}{$\begin{array}{c}\text { Perfil MP } 3 \text { - ARGISSOLO VERMELHO-AMARELO Distrófico típico } \\
\text { Áreas de Terra Firme do Alto Mapiá (Vista Alegre) }\end{array}$} \\
\hline A & $0-5$ & 41 & 28 & 19 & 12 & Franco-arenosa & $10 \mathrm{YR} 6 / 2$ \\
\hline BA & $5-15$ & 31 & 31 & 21 & 17 & Franco-arenosa & $10 \mathrm{YR} 6 / 3$ \\
\hline Bt1 & $15-35$ & 20 & 30 & 26 & 24 & Franco-argilo-arenosa & $10 \mathrm{YR} 6 / 6$ \\
\hline $\mathrm{Bt} 2$ & $35-75$ & 22 & 30 & 24 & 24 & Franco-argilo-arenosa & $10 \mathrm{YR} 6 / 6$ \\
\hline Bt3 & $75-160+$ & 22 & 30 & 23 & 25 & Franco-argilo-arenosa & 7,5 YR $7 / 6$ \\
\hline \multicolumn{8}{|c|}{$\begin{array}{c}\text { Perfil MP } 4 \text { - ARGISSOLO VERELHO-AMARELO Distrófico típico } \\
\text { Áreas de Encostas e Rampas (Vila Céu do Mapiá) }\end{array}$} \\
\hline $\mathrm{Ap}$ & $0-8$ & 25 & 48 & 17 & 10 & Franco-arenosa & $10 \mathrm{YR} 6 / 2$ \\
\hline $\mathrm{E}$ & $8-12$ & 24 & 55 & 14 & 7 & Areia-franca & $10 \mathrm{YR} 7 / 2$ \\
\hline BA & $12-20$ & 21 & 49 & 18 & 12 & Franco-arenosa & $10 \mathrm{YR} 7 / 3$ \\
\hline $\mathrm{Bt}_{1}$ & $20-40$ & 19 & 48 & 22 & 11 & Franco-arenosa & $10 \mathrm{YR} 7 / 3$ \\
\hline $\mathrm{Bt}_{2}$ & $40-80^{+}$ & 18 & 45 & 21 & 16 & Franco-arenosa & $10 \mathrm{YR} 7 / 4$ \\
\hline \multicolumn{8}{|c|}{$\begin{array}{l}\text { Perfil MP } 5 \text { - GLEISSOLO HÁPLICO Tb Distrófico } \\
\text { Aluviais Distróficas (Várzea do Alto Mapiá - Vila Céu do Mapiá) }\end{array}$} \\
\hline $\mathrm{A}_{1}$ & $0-10$ & 10 & 62 & 13 & 15 & Franco-arenosa & $10 \mathrm{YR} 7 / 3$ \\
\hline $\mathrm{AC}$ & $10-20$ & 1 & 22 & 32 & 45 & Argila & 7,5 YR 7/3 \\
\hline $\mathrm{CG}_{1}$ & $20-50$ & 1 & 17 & 38 & 44 & Argila & $10 \mathrm{YR} 8 / 3$ \\
\hline $\mathrm{CG}_{2}$ & $50-80^{+}$ & 3 & 44 & 33 & 20 & Franco & $10 \mathrm{YR} 8 / 4$ \\
\hline \multicolumn{8}{|c|}{$\begin{array}{l}\text { Perfil MP } 6 \text { - NEOSSOLO FLÚVICO Ta Eutrófico gleico } \\
\text { Planícies Aluviais Eutróficas (Várzeas do Purus) }\end{array}$} \\
\hline A & $0-5$ & 0 & 59 & 29 & 12 & Franco-arenosa & 10 YR $6 / 3$ \\
\hline $2 \mathrm{C}_{1}$ & $5-40$ & 0 & 50 & 37 & 13 & Franco & 10 YR 6/4 \\
\hline $3 \mathrm{C}_{2}$ & $40-80$ & 0 & 52 & 32 & 16 & Franco & $10 \mathrm{YR} 6 / 4$ \\
\hline $4 C_{3}^{2}$ & $80-120^{+}$ & 0 & 52 & 32 & 16 & Franco & $10 \mathrm{YR} 6 / 4$ \\
\hline
\end{tabular}


Nas áreas mais planas e elevadas predominam Latossolos Vermelho-Amarelos Distróficos típicos (LVAd), representados pelo perfil MP 1 (Tabela 3). São solos profundos e bem drenados, sem presença de plintita, com textura variando de franco-argilosa nos horizontes $A$ e $A B$ a argilosa nos horizontes mais profundos. Argissolos Vermelho-Amarelos Distróficos típicos (PVAd) com textura franco-arenosa no horizonte A passando a franco-argilo-arenosa no horizonte B textural (Bt), ocorrem em associação com o LVAd (Tabela 3 - Perfil MP 3). Do ponto de vista químico (Tabela 4), são solos ácidos, acentuadamente distróficos $(V<3 \%)$, com teores de alumínio muito elevados. Os teores de fósforo disponível são muito baixos, chegando a valores menores que $0,5 \mathrm{mg} / \mathrm{dm}^{3}$ no horizonte $B w$ ou $B t$. Os baixos valores de Prem indicam alta capacidade de adsorção de fosfato típica de solos cauliníticos-oxídicos comumente associados à Formação Solimões (LIMA, 2005).

São solos profundamente intemperizados e lixiviados nos quais a baixíssima disponibilidade de nutrientes e a alta atividade de $A l(m>90 \%)$ constituem limitações severas para o crescimento de espécies tradicionalmente cultivadas pela população local (milho, feijão, arroz de sequeiro e mandioca). A possibilidade de correção química é inviável dada a inacessibilidade do local pelas doses extremamente elevadas de insumos necessárias para a melhoria das características químicas desses solos.

Ainda que em níveis considerados limitantes, observam-se maiores teores de nutrientes disponíveis nos horizontes superficiais, evidenciando a importância da ciclagem de nutrientes pela vegetação nativa. Esse efeito é mais nítido para o perfil MP 2, no qual a saturação de alumínio é bastante reduzida nos primeiros $15 \mathrm{~cm}$ em relação aos horizontes mais profundos. Sabe-se que em condições amazônicas a mineralização da matéria orgânica é acelerada (SCHAEFER et al, 2000). Como a produção de biomassa é elevada, ocorre a contínua transformação do material vegetal depositado na superfície dos solos, disponibilizando nutrientes e reduzindo a atividade de $A l^{3+}$ no meio. A manutenção do crescimento do ecossistema de florestas se dá através de inúmeros mecanismos adaptativos de tolerância ao efeito fitotóxico do $\mathrm{Al}$ e a maior eficiência da ciclagem de nutrientes (SCHAEFER et al, 2000). A concentração elevada de raízes finas nos primeiros centímetros do solo, a associação com fungos micorrízicos e a liberação de exudatos radiculares são alguns destes mecanismos (SCHAEFER et al, 2000).

R. Árvore, Viçosa-MG, v.34, n.1, p.115-126, 2010
Do ponto de vista do uso do solo são áreas que devem ser cuidadosamente manejadas visando ao incremento dos teores de matéria orgânica no solo. A tradicional derrubada e queima para cultivo de culturas anuais devem ser evitadas. São áreas com aptidão para manejo florestal sustentável para produtos madeireiros e não madeireiros, plantios de enriquecimento e outros usos que favoreçam a presença de espécies perenes e a contínua ciclagem de nutrientes. Nas áreas atualmente sob cultivo e, ou, convertidas em pastagem, a melhoria das características do solo depende do desenvolvimento de sistemas específicos (agroflorestais ou agrossilvipastoris), utilizando-se espécies com baixa demanda nutricional e tolerantes ao $A l$.

As áreas de PVAd, uma vez removida a cobertura do solo, são muito suscetíveis à erosão laminar devido ao gradiente textural entre os horizontes $\mathrm{A}$ e Bt, acelerando-se a degradação da área.

\subsection{Encostas e rampas com mata sobre argissolos}

Esta unidade é composta pelos níveis intermediários e vertentes dos vales com dissecação pronunciada, com altitude variando de 120 a $160 \mathrm{~m}$. Constitui o geoambiente mais extenso da FLONA, recobrindo aproximadamente 64\% (164.201ha) da UC (Figura 2). Grande parte das moradias encontra-se nesse geoambiente. Predominam PVAd (Perfil MP 4) de textura franco-arenosa (Tabela 3).

Com relação às características químicas (Tabela 4), estes solos são igualmente ácidos e distróficos como aqueles descritos para os Platôs Dissecados. A CTC é extremamente baixa, variando de 1,9 a variando de 1,9 a 0.83 , sendo o intervalo entre esses valores variável ao longo do perfil. Observa-se o gradual aumento da saturação de alumínio em profundidade, chegando a mais de $90 \%$ no horizonte Bt 2 .

Essas características refletem a pobreza dos sedimentos da formação Solimões, submetidos a intenso intemperismo e lixiviação. Nessas condições, as cargas negativas e a disponibilidade de nutrientes dependem da fração orgânica do solo. Do ponto de vista agronômico são ambientes com baixa capacidade produtiva, sendo recomendada a utilização de corretivos e fertilizantes. O isolamento geográfico e o baixo nível tecnológico dos sistemas produtivos na FLONA inviabilizam a dependência de insumos externos. Portanto, devem ser incentivadas práticas de manejo que conduzam ao incremento do conteúdo de matéria orgânica no solo. 
Tabela 4-Características químicas selecionadas dos solos da FLONA do Purus, AM

Table 4-Selected chemical soil characteristics of the Purus FLONA, AM.

\begin{tabular}{lllcllllllllllll}
\hline Hor./ Prof. & $\mathrm{pH}$ & $\mathrm{P}$ & $\begin{array}{c}\mathrm{K} \\
\left(\mathrm{mg} / \mathrm{dm}^{3}\right)\end{array}$ & $\mathrm{Na}$ & $\mathrm{Ca}$ & $\mathrm{Mg}$ & $\begin{array}{c}\mathrm{Al} \\
\left(\mathrm{cmolc} / \mathrm{dm}^{3}\right)\end{array}$ & $\mathrm{H}-\mathrm{Al}$ & $\mathrm{CTC}$ & $\mathrm{V}$ & $\mathrm{M}$ & $\begin{array}{c}\mathrm{MO} \\
(\mathrm{g} / \mathrm{kg})\end{array}$ & $\begin{array}{c}\mathrm{Prem} \\
(\mathrm{mg} / \mathrm{L})\end{array}$ & $\begin{array}{c}\mathrm{Zn} \\
\mathrm{Fe} \\
(\mathrm{mg} / \mathrm{kg})\end{array}$ & $\begin{array}{c}\mathrm{Mn} \\
\mathrm{Cu}\end{array}$ \\
\hline
\end{tabular}

Perfil MP 1 -LATOSSOLO VERMELHO AMARELO distrófico típico

\begin{tabular}{cccccccccccccccccc}
\multicolumn{10}{c}{ Áreas de Terra Firme do Baixo Mapiá (Fazenda São Sebastião) } \\
$\mathrm{A}$ & 4,01 & 1,2 & 28 & 2,0 & 0,23 & 0,10 & 5,40 & 14,0 & 5,81 & 2,8 & 92,9 & 0,00 & 24,5 & 0,62 & 132,3 & 2,1 & 0,37 \\
$\mathrm{AB}$ & 4,30 & 0,5 & 14 & 0,0 & 0,19 & 0,04 & 5,80 & 12,0 & 6,07 & 2,2 & 95,6 & 4,35 & 16,1 & 0,27 & 127,4 & 1,6 & 0,61 \\
$\mathrm{Bw}_{1}$ & 4,51 & 0,6 & 9 & 0 & 0,15 & 0,04 & 5,8 & 10,6 & 6,04 & 2,25 & 96,0 & 2,20 & 14,8 & 2,26 & 107,9 & 1,1 & 4,51 \\
$\mathrm{Bw}_{2}$ & 4,91 & 0,2 & 4 & 2,0 & 0,32 & 0,04 & 6,20 & 10,7 & 6,58 & 3,4 & 94,2 & 1,00 & 12,3 & 0,00 & 19,6 & 1,0 & 0,28 \\
\hline
\end{tabular}

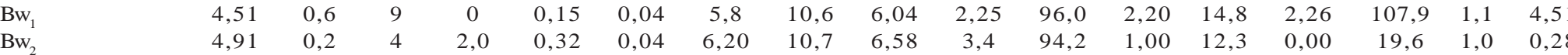
Perfil MP 2 - CAMBISSOLO HÁPLICO Ta eutrófico vértico

\begin{tabular}{lcccccccccccccccccc}
\multicolumn{10}{c}{ Planícies Aluviais Eutróficas (Várzea do Baixo Mapiá - Faz. São Sebastião) } \\
\hline A $0-8 \mathrm{~cm}$ & 4,97 & 7,4 & 63 & 23,0 & 13,14 & 3,01 & 6,00 & 12,0 & 22,41 & 57,8 & 26,8 & 2,86 & 16,8 & 3,44 & 154,3 & 73,1 & 2,63 \\
Bi $8-20 \mathrm{~cm}$ & 5,64 & 8,6 & 36 & 23,0 & 11,96 & 3,02 & 4,40 & 7,7 & 19,57 & 66,3 & 22,5 & 1,37 & 20,7 & 2,12 & 48,9 & 65,9 & 2,09 \\
C1 $20-40 \mathrm{~cm}$ & 6,00 & 9,7 & 40 & 40,0 & 17,63 & 3,57 & 1,20 & 5,1 & 22,67 & 80,8 & 5,3 & 1,37 & 23,8 & 1,12 & 43,6 & 19,4 & 1,75 \\
C2 $40-80 \mathrm{~cm}$ & 6,16 & 13,5 & 40 & 33,0 & 18,16 & 3,55 & 0,20 & 3,4 & 22,15 & 86,6 & 0,9 & 1,37 & 29,6 & 1,12 & 32,4 & 16,8 & 1,54
\end{tabular}
Perfil MP 3-ARGISSOLO VERMELHO AMARELO distrófico típico

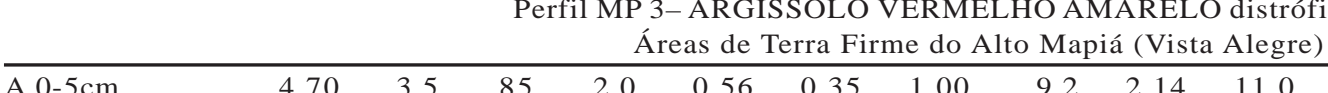

\begin{tabular}{|c|c|c|c|c|c|c|c|c|c|c|c|c|c|c|c|c|c|}
\hline A $0-5 \mathrm{~cm}$ & 4,70 & 3,5 & 85 & 2,0 & 0,56 & 0,35 & 1,00 & 9,2 & 2,14 & 11,0 & 46,7 & 3,48 & 44,8 & 1,37 & 90,0 & 23,1 & 0,12 \\
\hline BA $5-15 \mathrm{~cm}$ & 5,02 & 0,7 & 20 & 2,0 & 0,87 & 0,78 & 0,80 & 5,6 & 2,51 & 23,4 & 31,9 & 2,86 & 37,2 & 0,28 & 178,5 & 21,3 & 0,05 \\
\hline Bt $115-35 \mathrm{~cm}$ & 4,52 & 0,4 & 7 & 2,0 & 0,08 & 0,02 & 2,80 & 5,9 & 2,93 & 2,2 & 95,6 & 1,62 & 23,4 & 0,00 & 108,1 & 1,5 & 0,00 \\
\hline Bt2 $35-75 \mathrm{~cm}$ & 4,51 & 0,1 & 5 & 2,0 & 0,02 & 0,00 & 2,40 & 4,9 & 2,44 & 0,8 & 98,4 & 1,00 & 25,1 & 0,00 & 92,3 & 0,8 & 0,01 \\
\hline BC $75-160 \mathrm{~cm}$ & 4,43 & 0,0 & 5 & 1,0 & 0,03 & 0,01 & 2,80 & 4,3 & 2,85 & 1,1 & 98,2 & 0,37 & 30,0 & 0,05 & 15,6 & 0,2 & 0,00 \\
\hline \multicolumn{18}{|c|}{$\begin{array}{c}\text { Perfil MP } 4 \text { - ARGISSOLO VERELHO AMARELO distrófico típico } \\
\text { Áreas de Encostas e Rampas (Vila Céu do Mapiá) }\end{array}$} \\
\hline Ap $0-8 \mathrm{~cm}$ & 5,09 & 3,2 & 31 & 2,0 & 0,74 & 0,67 & 0,40 & 5,3 & 1,90 & 22,1 & 21,1 & 3,48 & 52,2 & 2,62 & 54,3 & 38,5 & $\overline{0,48}$ \\
\hline E $8-12 \mathrm{~cm}$ & 4,90 & 1,2 & 14 & 2,0 & 0,23 & 0,15 & 0,40 & 2,6 & 0,83 & 14,2 & 48,2 & 1,24 & 53,5 & 0,39 & 75,8 & 9,1 & 0,34 \\
\hline BA $12-20 \mathrm{~cm}$ & 4,71 & 0,8 & 14 & 2,0 & 0,17 & 0,11 & 1,20 & 4,0 & 1,53 & 7,6 & 78,4 & 1,87 & 43,4 & 0,00 & 184,4 & 4,0 & 0,17 \\
\hline Bt1 $20-40 \mathrm{~cm}$ & 4,76 & 0,3 & 22 & 2,0 & 0,08 & 0,05 & 1,40 & 3,6 & 1,60 & 5,3 & 87,5 & 1,37 & 33,4 & 0,00 & 188,5 & 3,6 & 0,27 \\
\hline Bt2 $40-80 \mathrm{~cm}$ & 5,04 & 0,1 & 19 & 2,0 & 0,04 & 0,04 & 1,60 & 3,6 & 1,74 & 3,7 & 92,0 & 0,75 & 32,1 & 0,00 & 87,3 & 2,2 & 0,15 \\
\hline \multicolumn{18}{|c|}{ Perfil MP 5 - GLEISSOLO HÁPLICO Tb distrófico } \\
\hline$\overline{A_{1} 0-10}$ & 4,38 & 3,4 & 37 & 0,0 & 0,00 & 0,03 & 1,50 & 4,0 & 1,62 & 2,9 & 92,6 & 2,57 & 39,1 & 2,25 & 370,3 & 16,5 & $\overline{0,19}$ \\
\hline AC $10-20$ & 4,66 & 0,8 & 9 & 0,0 & 0,00 & 0,06 & 5,40 & 7,9 & 5,48 & 1,0 & 98,5 & 1,90 & 19,9 & 2,58 & 58,6 & 13,1 & 0,11 \\
\hline $\mathrm{CG}_{1} 20-50$ & 5,32 & 0,9 & 7 & 48 & 0,00 & 0,55 & 5,10 & 8,4 & 5,88 & 8,5 & 86,7 & 2,13 & 17,2 & 1,65 & 38,2 & 22,9 & 0,00 \\
\hline $\mathrm{CG}_{2} 50-80^{+}$ & 4,32 & 2,4 & 10 & 2,2 & 0,11 & 0,00 & 3,10 & 4,9 & 3,25 & 3,0 & 95,4 & 2,57 & 27,2 & 2,52 & 318,0 & 19,7 & 0,13 \\
\hline \multicolumn{18}{|c|}{$\begin{array}{c}\text { Perfil MP } 6 \text { - NEOSSOLO FLÚVICO Ta eutrófico gleico } \\
\text { Planícies Aluviais Eutróficas (Várzeas do Purus) }\end{array}$} \\
\hline A $0-5 \mathrm{~cm}$ & 6,17 & 29,5 & 180 & 11,0 & 8,88 & 2,23 & 0,00 & 1,0 & 11,62 & 92,1 & 0,0 & 1,24 & 47,4 & 1,28 & 61,6 & 71,9 & $\overline{1,12}$ \\
\hline $2 \mathrm{C} 15-40 \mathrm{~cm}$ & 6,39 & 17,3 & 58 & 16,0 & 12,25 & 2,61 & 0,00 & 1,7 & 15,08 & 89,9 & 0,0 & 0,00 & 39,7 & 0,90 & 72,2 & 44,1 & 1,15 \\
\hline $3 \mathrm{C} 2 \quad 40-80 \mathrm{~cm}$ & 6,48 & 18,6 & 62 & 17,0 & 12,78 & 2,72 & 0,00 & 1,0 & 15,73 & 94,0 & 0,0 & 1,24 & 37,3 & 1,14 & 100,9 & 67,5 & 1,26 \\
\hline $4 C 380-120+$ & 6,99 & 16,7 & 65 & 18,0 & 12,52 & 2,68 & 0,00 & 0,7 & 15,45 & 95,7 & 0,0 & 1,24 & 33,8 & 1,11 & 100,0 & 72,9 & 1,18 \\
\hline
\end{tabular}


Tradicionalmente, desde o início da ocupação da FLONA são áreas usadas para o cultivo anual seguindo o modelo de derrubada e queima da floresta, cultivo por três anos e abandono para pousio ou conversão em pastagens com baixa capacidade de suporte. Devido à elevada pressão de uso, as áreas sob uso apresentam-se frequentemente degradadas, com evidências de erosão laminar severa e formação de sulcos erosivos.

Do ponto de vista físico, a textura franco-arenosa sugere uma boa permeabilidade. Esse aspecto deve ser mais bem avaliado para o planejamento da ocupação humana no que diz respeito a questões sanitária e a captação de água potável, de forma a evitar a contaminação de águas subterrâneas em função da disposição inadequada de esgotos domésticos.

\subsection{Planícies Aluviais Eutróficas com Neossolos Flúvicos e Gleissolos}

Constituem as áreas de várzea sobre influência do rio Purus e Inauini (Figura 2) e representam 5\% (11.840 ha) da área total da FLONA.

\subsubsection{Várzeas do Purus}

Durante o período mais seco do ano, ocorre a drástica redução da vazão dos rios e igarapés, resultando no surgimento de extensas praias aluviais, com texturas variáveis, desde arenosa e siltosa até argila. Ao longo do rio Purus, essas áreas são intensamente utilizadas por ribeirinhos para o cultivo de culturas anuais (arroz, milho, feijão, abóbora e melancia, entre outras), garantindo a subsistência de diversas famílias. São observados pelo menos dois níveis inundáveis. O MP 6, Neossolo Flúvico Ta Eutrófico gleissólico (RYve), é representativo destes geoambientes. Estes solos são formados a partir de sedimentos ricos de proveniência subandina.

São solos com $\mathrm{pH}>6$, teores elevados de $\mathrm{P}$ disponível, Ca e Mg trocáveis, com saturação de bases próximo de $100 \%$ e CTC elevada (Tabela 4), em função da presença de argilas de atividade alta. Apresentam textura franco-arenosa no horizonte A e franca nos demais (Tabela 3). Constituem, de todos os solos analisados, os mais adequados para a produção sustentável de culturas anuais. A deposição anual de novos sedimentos garante a "fertilização" natural da safra seguinte. Em níveis de praia mais elevados, onde as enchentes são menos comuns, os teores de nutrientes são menores (cerca de 50\% do teor de P, Ca e Mg), porém ainda altos quando comparados com os solos de Terra Firme (dados não apresentados).

\subsubsection{Várzeas do Baixo Mapiá}

A várzea do baixo curso do Igarapé Mapiá é formada por níveis sedimentares aplainados inundáveis, cobertos originalmente por floresta aluvial, com espécies adaptadas ao excesso de água no solo. Durante grande parte do ano, estas áreas se apresentam alagadas, com influência de sedimentos do Purus.

O perfil MP2, classificado como Cambissolo Háplico Ta Eutrófico vertissólico (CXve), apresenta alta saturação de bases (Tabela 4), com características vérticas como fendas, slikensides e estrutura prismática. Essa parte do Igarapé Mapia é fortemente influenciada pelas "águas brancas" do rio Purus, que nas épocas de cheia "invadem" a calha do Mapiá, a montante de sua embocadura, misturando-se à água escura e formando extensas áreas alagadas que cobrem as várzeas. Na vazante, são depositados sedimentos ricos em nutrientes nessas várzeas. São solos argilosos gleizados com textura argilosiltosa no horizonte A e franco-argilo-siltosa nos horizonte mais profundos (Tabela 4).

Apesar do caráter eutrófico (saturação de bases no complexo de troca $>60 \%$ ) e dos teores extremamente altos de $\mathrm{Ca}^{2+}$ e $\mathrm{Mg}^{2+}$, são observados, até os $20 \mathrm{~cm}$ de profundidade, valores de $A l^{3+}$ comparáveis aos observados nos solos de Terra Firme. A CTC é muito elevada, em função da presença de argilas de atividade alta. Apesar dos valores relativamente baixos de Prem, quando comparados com os demais solos estudados, observase razoável disponibilidade de $P$, constituindo um ambiente favorável ao desenvolvimento de culturas anuais.

\subsubsection{Várzeas do Inauini}

Neste trabalho não foram amostrados solos nesta unidade, sendo utilizada a descrição publicada em Brasil (1976). As várzeas do rio Inauini são formadas por sedimentos Quaternários, de textura geralmente argilosiltosa, sustentando uma vegetação de Floresta Ombrófila Densa Aluvial (BRASIL, 1976). São solos aluviais, de fertilidade alta, com saturação de bases variando de $55 \%$ a 93\%, alta CTC e teores de matéria orgânica altos nos horizontes superficiais. Os solos dessas áreas são classificados como Gleissolos Háplicos Ta Eutróficos, que ocorrem associados em caráter dominante ao Argissolo Vermelho-Amarelo (BRASIL, 1976). 


\subsection{Planícies Aluviais Distróficas com Gleissolos}

Constituem as áreas de várzea dos igarapés, formadas pela deposição de sedimentos relacionados à Formação Solimões e representam o geoambiente de menor ocorrência na FLONA, com aproximadamente 2.117 ha $(1 \%)$.

O perfil MP 5, representativo desse geoambiente, descrito para o primeiro nível de terraço da margem direita do igarapé Mapiá, nas proximidades da Vila Céu do Mapiá, foi classificado como Gleissolo Háplico Tb distrófico (GXbd). São solos gleizados, de textura predominantemente argilosa (Tabela 3 ).

Do ponto de vista químico, apresentam alta saturação por alumínio $(\mathrm{m}>80 \%)$ e baixa saturação por bases $(\mathrm{V}<50 \%)$, com teores praticamente nulos de $\mathrm{Na}, \mathrm{Ca}^{2+} e \mathrm{Mg}^{2+}$ (Tabela 4). Os valores reduzidos de Prem indicam alta capacidade de adsorção de fosfato, reduzindo a disponibilidade de $P$ para as plantas.

Apesar de constituírem áreas de várzea, a pobreza química dos sedimentos depositados desfavorece a implantação dos cultivos anuais. Portanto, do ponto de vista do uso do solo, é recomendável o reflorestamento com espécies adaptadas ao excesso de água, buscando reconstituir a mata ciliar que originalmente recobria essas áreas.

\section{CONCLUSÕES}

Na FLONA do Purus, os geoambientes relacionados às planícies aluviais sob influência dos rio Purus e Inauini apresentam solos eutróficos, constituindo áreas adequadas para a implementação de culturas anuais nas áreas de vazantes e praias. A manutenção da produtividade ao longo dos anos nesses solos é garantida pela renovação da fertilidade em função da deposição sazonal de sedimentos durante os períodos de cheia dos rios. No âmbito do Plano de Manejo da FLONA, são áreas que devem ser incorporadas na zona de produção agrícola.

A maior capacidade de suporte das áreas de vazante do Purus e do Inauini denota a necessidade de rever as estratégias de ocupações agrícola e pastoril da FLONA do Purus visto que o cultivo do eixo de Terra-Firme do igarapé Mapiá vem gradualmente conduzindo a exaustão e degradação dos solos.

Em contraste, todos os demais geoambientes da FLONA possuem solos fortemente ácidos e pobres em nutrientes, formados a partir de sedimentos da Formação
Solimões. Nestes, a deficiência de $P$ e a alta saturação de $A l$ são fatores destacados na limitação ao uso. Devem ser incentivadas práticas de manejo que visem ao incremento da matéria orgânica nos solos, visto que esta é responsável pela geração de cargas elétricas negativas e disponibilização de nutrientes via ciclagem biogeoquímica.

A adequação da legislação ambiental em função da realidade amazônica e o desenvolvimento de modelos de ocupação sustentáveis nas várzeas eutróficas são temas urgentes para a solução dos conflitos de uso da terra e melhoria da qualidade de vida das populações ribeirinhas.

\section{REFERÊNCIAS}

BRASIL. Ministério das Minas e Energia. Departamento Nacional da Produção Mineral. RADAMBRASIL: Folha SC.19 Rio Branco: geologia, geomorfologia, pedologia, vegetação e uso potencial da terra. Rio de Janeiro: 1976. 12v. 464p.

BRASIL. Lei $\mathbf{n}^{\circ} 9.985$, de 18 de julho de 2000. Regulamenta o art. $225, \S 1^{\circ}$, incisos I, II, III e IV da Constituição Federal, institui o Sistema Nacional de Unidades de Conservação da Natureza - SNUC e dá outras providências. Brasília: MMA/SBF, 2000. 32p.

EMPRESA BRASILEIRA DE PESQUISA AGROPECUÁRIA - EMBRAPA. Centro Nacional de Pesquisa de Solos. Manual de métodos de análise de solo. 2.ed. Rio de Janeiro: Centro Nacional de Pesquisa de Solos, 1997. 212p.

EMPRESA BRASILEIRA DE PESQUISA AGROPECUÁRIA - EMBRAPA. Centro Nacional de Pesquisa de Solos. Sistema brasileiro de classificação de solos. 2.ed. Rio de Janeiro: 2006. v.26. 412p.

ESPIRITO-SANTO, F. B.; SHIMABUKURO, Y. E. Validação do mapeamento de uma área de floresta tropical com o uso imagens de videografia aérea e dados de levantamento de campo. Revista Árvore, v.29, n.2, p.227-239, 2005.

INSTITUTO BRASILEIRO DO MEIO AMBIENTE E DOS RECURSOS NATURAIS RENONÁVEIS IBAMA. Roteiro metodológico para elaboração de plano de manejo para florestas nacionais. Brasília: 2003. 56p.

R. Árvore, Viçosa-MG, v.34, n.1, p.115-126, 2010 
FUNDAÇÃO INSTITUTO BRASILEIRO DE GEOGRAFIAE ESTATÍSTICA - IBGE.

Diagnóstico geoambiental e sócioeconômico: área de influência da BR-364 trecho Porto Velho/Rio Branco. Rio de Janeiro: 1990. v.1. 132p.

ISA. Instituto Socioambiental (São Paulo, SP). Amazônia brasileira 2004. São Paulo: 2004. Escala 1:4.000.000.

LEMOS, R. C.; SANTOS, R. D. Manual de descrição e coleta de solo no campo. 2.ed. Campinas: SBCS/SNLCS, 1984. 45p.

LIMA, H. N. et al. Dinâmica da mobilização de elementos em solos da Amazônia submetidos à inundação. Acta Amazonica, v.35, n.3, p.317330, 2005.

MARTINS, I. C. M. Diagnóstico ambiental no contexto da paisagem de fragmentos florestais naturais "Ipucas" - no município de Lagoa da Confusão, Tocantins. 1999. 97f. Dissertação (Mestrado em Ciência Florestal) - Universidade Federal de Viçosa, 1999.

MARTINS, A. K. et al. Relações solo-geoambiente em áreas de ocorrências de Ipucas na planície do Médio Araguaia - Estado de Tocantins. Revista Árvore, v.30, n.2, p.297-310, 2006
MÜNSELL. Soil Color Charts. Baltimore: Munsell Color Company, 1994. 28p.

QUINET, A. et al. Inventário florístico para Avaliação Ecológica Rápida (AER) da Floresta Nacional do Purus. Rio Branco: 2005. 30p.

RICARDO, F. Sobreposições entre Unidades de Conservação (UCs) federais, estaduais, terras indígenas, terras militares, e reservas garimpeiras na Amazônia Legal. In: COPOBIANCO, J. P. R. et al. (Orgs.). Biodiversidade na Amazônia Brasileira: avaliação e ações prioritárias para a conservação, uso sustentável e repartição de benefícios. São Paulo: Estação Liberdade: Instituto Socioambiental, 2001. p.259-262.

SCHAEFER, C. E. R. et al.. Uso do solos e alterações da paisagem na Amazônia, cenários e reflexões. Boletim Museu Goeldi, Série Ciência da Terra, v.12, p.63-104, 2000.

SCHAEFER, C. E. R. Ecogeography and Human Scenario in Roraima, Amazônia. Ciência e Cultura, v.49, n.4, p.241-252, 1997.

TRICART, J.; KIEWITDEJONGE, C.

Ecogeography and rural management. Harlowl: Longman Scientific, 1992. 